\title{
sciendo
}

\section{Implantation and pregnancy outcome of Sprague-Dawley rats exposed to pirimiphos-methyl}

\author{
Tolulope Oyesola ${ }^{1}$, Bolanle Iranloye ${ }^{2}$, Olufeyi Adegoke ${ }^{2}$ \\ ${ }^{1}$ Department of Physiology, Benjamin Carson Senior School of Medicine, College of Health and Medical Sciences, \\ Babcock University, Ilishan-Remo, Ogun state, Nigeria; ${ }^{2}$ Department of Physiology, College of Medicine of the University \\ of Lagos, Lagos, Nigeria \\ E-mail: oyesolat@babcock.edu.ng
}

Objective. This study was designed to investigate the effect of sublethal doses $(10,60$, and 120 $\mathrm{mg} / \mathrm{kg}$ of pirimiphos-methyl on implantation and pregnancy in female Sprague-Dawley rats. Pirimiphos-methyl is a pesticide widely used worldwide, especially in Africa to protect food against pests and has gained widespread acceptance.

Methods. Pregnant Sprague-Dawley rats used for this study had access to food and water ad libitum and were divided into a control group and three experimental groups based on dose of chemical given. The pregnant rats were given pirimiphos-methyl orally on days $1-5,1-7,7-18^{\text {th }}$ day of gestation and from day 1 to term. Implantation studies were carried out on days 6 and 8 of pregnancy, while the fetal parameters were ascertained on day 19 of pregnancy and at term. Serum levels of progesterone and estradiol were measured on days 6, 8 and 19 of pregnancy.

Results. Sublethal administration of pirimiphos-methyl showed decreased number of implantation sites on days 6 and 8, fetal weight, crown-to-rump length, length of umbilical cord and placenta weight (day 19), birth weight, litter size and total number (at term) in rats administered with pirimiphos-methyl when compared with control.

Conclusion. Administration of pirimiphos-methyl resulted in a reduced implantation rate due to decreased uterine receptivity caused by an imbalance in the level of estradiol and progesterone and impaired reproductive outcome during pregnancy.

Key words: pesticide, pirimiphos-methyl, implantation, pregnancy, sublethal dose

Fertilization, which usually occurs in the oviduct, is followed by time-dependent mitotic division in the egg, while trying to reach the blastocyst stage and the uterus for implantation. Implantation is a process, by which the blastocyst comes into the intimate physical and physiological contact with the uterine endometrium, which is an absolute requirement for further growth and collection of nutrients from the maternal vasculature. The implantation process is a critical event in the embryo's life and a central step to the establishment of placentation and pregnancy (Deb et al. 2006). Implantation in rats is initiated on day 5 and completed by day 7 of the pregnancy (Hamid et al. 2012). During the implantation period, the endometrium undergoes a transition and acquires an appropriate morphological and functional state under the influence of progesterone and estrogen, which are the dominant hormonal modulators of the endometrial development. Pregnancy outcome, which is the final result of fertilization and conception, includes sex ratio, live birth, birth weight, spontaneous abortion, lower birth weight, preterm delivery or stillbirth.

Corresponding author: Tolulope Oyesola, Department of Physiology, Benjamin Carson (Snr) School of Medicine, College of Health and Medical Sciences, Babcock University, P.M.B. 21244, Ikeja, Lagos; phone: 08062217381; e-mail address: oyesolat@babcock.edu.ng. 
Organophosphorus pesticides or organophosphates (OP) are a group of pesticides widely used as insecticides including agriculture (Koch et al. 2002; Berkowitz et al. 2003). Routes of exposure to humans include inhalation, absorption through skin or eyes, and ingestion (Gallo and Lawryk 1991). The primary toxicity associated with acute exposure to OP insecticides is cholinergic crisis resulting from acetylcholinesterase inhibition (Pope 1999; Cabello et al. 2001). The use of pesticides could affect non-target organisms and wildlife in the ecosystem and ultimately human health leading to various effects like immunotoxicity, carcinogenesis, endocrine, and developmental toxicity. Experimental evidences from both human and animal studies have suggested exposure to pesticides poses a greater risk of adverse reproductive outcomes (Hayes and Laws 1991). The OP exposure has been linked to reproductive disorders such as infertility, birth defects, adverse pregnancy outcomes (spontaneous abortions and fetal death), and perinatal mortality (Baldi et al. 1998; Sanborn et al. 2002; Recio et al. 2005).

Pirimiphos-methyl(O-[2-(Diethylamino)-6-methylpyrimidin-4-yl] O,O-dimethyl phosphorothioate) is a broad spectrum of non-cumulative organophosphate pesticides. Pirimiphos-methyl has widespread agricultural and domestic uses, both as an acaricide and insecticide, on pest in stored grains as well as in household and catering establishment (Tamura et al. 2001). It has been reported to have adverse effects on male reproductive functions (Ngoula et al. 2007) as well as causing ovarian cycle irregularities in female rats (Iranloye and Oyesola 2018) even though OECD regulation classify it as being neither a reprotoxin nor a teratogen. This study was undertaken to determine the effect of administration of sublethal doses of pirimiphos-methyl on implantation and pregnancy outcome in female Sprague-Dawley rats.

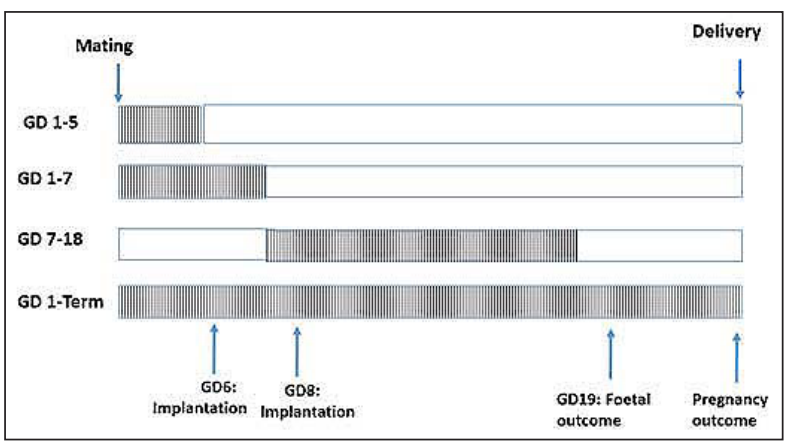

Figure 1. Overview of the experimental design. $\mathbf{m}$ |lm $\mathbf{l}$ - Period of pirimiphos-methyl exposure. Abbreviation: GD - gestational day.

\section{Materials and methods}

Animals. Sexually matured female and male rats (160-180 g) of the Sprague-Dawley strain obtained from the Animal House of the College of Medicine, University of Lagos, were used. The rats were acclimatized for 2 weeks under standard conditions $\left(28 \pm 2^{\circ} \mathrm{C}\right.$, humidity at $70 \%, 12$-h light and dark cycle, 6 animals housed per cage and fed commercial diet and water ad libitum). All guidelines with the use and care of laboratory animals were strictly adhered to in accordance with the U.S. National Institute of Health. This study was approved by the College of Medicine, University of Lagos Health Research Ethical Committee. The female rats were divided into four treatment groups: Group A - distilled water (control); Group B - $10 \mathrm{mg} / \mathrm{kg}$ of pirimiphos-methyl $\left(\sim 0.8 \% \mathrm{LD}_{50}\right)$; Group C $-60 \mathrm{mg} / \mathrm{kg}$ of pirimiphosmethyl $\left(\sim 5 \% \mathrm{LD}_{50}\right)$; Group D - $120 \mathrm{mg} / \mathrm{kg}$ of pirimiphos-methyl $\left(\sim 10 \% \mathrm{LD}_{50}\right)$.

Chemicals. An organophosphate pesticide, pirimiphos-methyl (PM) (Emulsifiable concentrate, 250 g/l, Batch no: CHL5G11-06, Syngenta, UK) with the chemical name O-[2-(Diethylamino)-6-methylpyrimidin-4-yl] O,O-dimethyl phosphorothioate, $\mathrm{C}_{11} \mathrm{H}_{20} \mathrm{~N}_{3} \mathrm{O}_{3} \mathrm{PS}$, was used in the study. The CAS Number is 29232-93-7 with formula weight 305.33. The purity (HPLC AREA \%) is $\geq 98.0 \%$. Percentage of the $\mathrm{LD}_{50}$ was calculated from the dose previously used by Ngoula et al. (2007).

Experimental design. Ninety-six (96) female rats and twenty-four (24) male rats were used for this study. Proestrus phase was determined by means of vaginal cytology. A male rat was introduced to two female rats on the evening of proestrus (05:0006:00 p.m.) for mating, which was confirmed by the presence of sperm cells in the vagina smear of the rats, the following morning (08:00-09:00 a.m.) and that day was taken as day one of pregnancy (Figure 1).

Implantation study was carried out on six rats, each from the study groups, as it has been described by Iranloye et al. (2010). Rats received various doses of PM on the postnatal days (PND) 1-5 (early implantation), 1-7 (late implantation), 7-18 $8^{\text {th }}$ (post-implantation) and from day 1 to term and were sacrificed on gestation days (GD) 6, 8 and 19. A group was allowed to term to assess pregnancy outcome. Blood collection was done via cardiac puncture.

Determination of implantation sites. In rats, considering the presence of sperm in the vaginal smear as day 1 of gestation, implantation sites can be detected as early as on day 4 of pregnancy (10:0011:00 p.m.) and onward. Rats were injected with 
$1 \mathrm{mg} / \mathrm{ml}$ Evans blue via the rat tails vein and allowed to circulate for about $15 \mathrm{~min}$. Then, the rats were sacrificed by cervical dislocation and the implantation sites were observed and counted in the uterus of the rats (Dey et al. 2004; Iranloye et al. 2010).

Studies on pregnancy and pregnancy outcomes. The first group of rats received PM orally from GD7 till GD18 while the second group received PM from GD1 till term. The following parameters were observed and recorded: placental weight, number of fetuses, fetal weight, length of umbilical cord and crown-to-rump length were measured and recorded on day 19. Gestation length, litter size, birth weight and total number of pups born in the rats that were allowed to term. The weaning index and viability index calculated on PND4 and PND21, respectively.

Determination of hormone levels. Blood samples collected on days 6,8 , and 19 of pregnancy via cardiac puncture. Serum from blood samples were assayed for estradiol and progesterone using EnzymeLinked-Immunosorbent Serologic Assay (ELISA) techniques. The assay kits were obtained from Elabscience Biotechnology Co., Ltd, (Wuhan, China).

Statistical analysis. All the values are expressed as mean \pm standard error of mean (SEM). The values were analyzed by one-way ANOVA followed by Student's Newman-Keuls post hoc test using the Graph Pad software. Differences were considered significant when $\mathrm{p}<0.05$.

\section{Results}

Effect of PM on implantation. The effect of administration of PM on the number of implantation sites in pregnant rats sacrificed on GD6 and GD8 is shown in Table 1. Number of implantation sites was significantly $(p<0.05)$ decreased in PM-treated rats sacrificed on days 6 in groups B, C and D when compared with group A. Similar pattern was observed on day 8 in groups B, C and D when compared with control.

Effect of PM on pregnancy and pregnancy outcome. The effect of administration of PM on pregnancy outcome on day 19 is shown in Table 2. The weight of the fetuses on day 19 was significantly $(\mathrm{p}=0.0001)$ decreased in groups $\mathrm{B}, \mathrm{C}$ and $\mathrm{D}$ compared with the control. Placenta weight on day 19 was significantly $(p=0.0001)$ decreased in groups $B, C$ and $\mathrm{D}$ when compared with the control. The crownto-rump length of litters on day 19 was significantly decreased in groups $B, C$ and $D(p=0.0001)$ when compared with the control. The length of umbilical cord was significantly $(\mathrm{p}=0.0233)$ decreased in group $\mathrm{D}$ when compared with control but no significant difference in groups B and C. However, there was no significant difference between the fetal number between groups B, C and D when compared with the control.

The effect of administration of PM from day 1 of gestation to term is shown in Table 3. Average litter weight was significantly $(\mathrm{p}=0.0297)$ decreased in groups $\mathrm{B}$ and $\mathrm{C}$ as well as total number of pups

Table 1

Effect of pirimiphos-methyl on number of implantations.

\begin{tabular}{lccc}
\hline Group & $\begin{array}{c}\text { Treatment } \\
\text { PM } \\
(\mathbf{m g} / \mathbf{k g})\end{array}$ & $\begin{array}{c}\text { Number of } \\
\text { implantation site } \\
(\text { day 6) }\end{array}$ & $\begin{array}{c}\text { Number of } \\
\text { implantation site } \\
(\text { day 8) }\end{array}$ \\
\hline A & Control & $8.00 \pm 0.53$ & $7.50 \pm 0.39$ \\
B & 10 & $5.50 \pm 0.20^{*}$ & $5.50 \pm 0.20^{*}$ \\
C & 60 & $4.50 \pm 0.39^{*}$ & $3.67 \pm 0.19^{*}$ \\
D & 120 & $3.00 \pm 0.71^{*}$ & $2.33 \pm 0.45^{*}$ \\
\hline
\end{tabular}

Group A - rats in the control group administered with distilled water only; Group B - rats administered at a dose of $10 \mathrm{mg} / \mathrm{kg}$ of pirimiphos-methyl; Group C - rats administered at a dose of $60 \mathrm{mg} / \mathrm{kg}$ of pirimiphos-methyl; Group D - rats administered at a dose of $120 \mathrm{mg} / \mathrm{kg}$ of pirimiphos-methyl. ${ }^{*} \mathrm{p}<0.05 \mathrm{vs}$. control (Group A).

Table 2

Effect of pirimiphos-methyl on pregnancy outcome in rats administered from GD7 to GD18 of pregnancy.

\begin{tabular}{|c|c|c|c|c|}
\hline Parameter & Group A & Group B & Group C & Group D \\
\hline Number of fetuses (Day 19) & $8.00 \pm 0.37$ & $8.00 \pm 0.37$ & $8.20 \pm 0.70$ & $7.70 \pm 0.21$ \\
\hline Weight of fetuses (g) (Day 19) & $2.10 \pm 0.04$ & $1.40 \pm 0.06^{*}$ & $1.30 \pm 0.05^{\star}$ & $1.10 \pm 0.12^{\star}$ \\
\hline Weight of placenta (g) (Day 19) & $0.70 \pm 0.01$ & $0.50 \pm 0.02^{\star}$ & $0.50 \pm 0.02^{\star}$ & $0.50 \pm 0.04^{*}$ \\
\hline Length of umbilical cord $(\mathrm{cm})$ & $2.40 \pm 0.11$ & $2.20 \pm 0.06$ & $2.00 \pm 0.12$ & $1.90 \pm 0.09^{*}$ \\
\hline Crown-rump length $(\mathrm{cm})$ & $4.20 \pm 0.04$ & $3.70 \pm 0.07^{\star}$ & $3.60 \pm 0.08^{*}$ & $3.40 \pm 0.18^{\star}$ \\
\hline
\end{tabular}

Group A - rats in the control group administered with distilled water only; Group B - rats administered with a dose of $10 \mathrm{mg} / \mathrm{kg}$ of pirimiphos-methyl; Group C - rats administered with a dose of $60 \mathrm{mg} / \mathrm{kg}$ of pirimiphos-methyl; Group D - rats administered with a dose of $120 \mathrm{mg} / \mathrm{kg}$ of pirimiphos-methyl. ${ }^{\star} \mathrm{p}<0.05 \mathrm{vs}$. control (Group A). Abbreviation: GD - gestational day. 
Table 3

Effect of pirimiphos-methyl on pregnancy outcome in rats administered from GD1 to term.

\begin{tabular}{lcccc}
\hline Parameters & Group A & Group B & Group C & Group D \\
\hline Weight of litter (g) at birth & $5.22 \pm 0.21$ & $4.68 \pm 0.03^{*}$ & $4.01 \pm 0.21^{*}$ & 0 \\
Gestation length (days) & $22.00 \pm 0.21$ & $22.50 \pm 0.22$ & $23.3 \pm 0.21$ & 0 \\
Litter size & $8.00 \pm 0.73$ & $7.50 \pm 0.22$ & $6.5 \pm 0.21^{*}$ & 0 \\
Total no. of pups born & $48.00 \pm 0.73$ & $44.00 \pm 0.21^{*}$ & $39 \pm 0.34^{*}$ & 0 \\
Birth index (\%) & 100.00 & 100.00 & $61.50 \pm 0.21^{*}$ & 0.00 \\
Viability index (\%) & 100.00 & 100.00 & 0.00 & 0.00 \\
Weaning index (\%) & $95.17 \pm 3.68$ & $92.95 \pm 3.15$ & 0.00 & 0.00 \\
\hline
\end{tabular}

Group A - rats in the control group administered with distilled water only; Group B - rats administered with a dose of $10 \mathrm{mg} / \mathrm{kg}$ of pirimiphos-methyl; Group C - rats administered with a dose of $60 \mathrm{mg} / \mathrm{kg}$ of pirimiphos-methyl; Group D - rats administered with a dose of $120 \mathrm{mg} / \mathrm{kg}$ of pirimiphos-methyl. Birth index was calculated as number of live offspring divided by number of offspring delivered multiplied by $100 \%$. Viability index was calculated as number of live offspring at postnatal day 4 divided by number of live offspring delivered multiplied by $100 \%$. Weaning index was calculated as number of live offspring at postnatal day 21 divided by number of live offspring born multiplied by $100 \% .{ }^{*} \mathrm{p}<0.05 \mathrm{vs}$. control (Group A). Abbreviation: GD - gestational day.

Table 4

Estradiol levels $(\mathrm{pg} / \mathrm{ml})$ at different days of pregnancy in rats administered with pirimiphos-methyl during pregnancy.

\begin{tabular}{lcccc}
\hline & Group A & Group B & Group C & Group D \\
\hline Day 6 & $6.90 \pm 0.56$ & $8.80 \pm 1.46$ & $7.30 \pm 0.24$ & $5.00 \pm 2.27$ \\
Day 8 & $20.10 \pm 1.12$ & $10.00 \pm 1.15^{*}$ & $11.00 \pm 1.08^{*}$ & $11.40 \pm 2.20^{*}$ \\
Day 19 & $27.50 \pm 1.90$ & $19.10 \pm 2.72^{\star}$ & $15.30 \pm 1.53^{*}$ & $6.10 \pm 1.15^{*}$ \\
\hline
\end{tabular}

Group A - rats in the control group administered with distilled water only; Group B - rats administered with a dose of $10 \mathrm{mg} / \mathrm{kg}$ of pirimiphos-methyl; Group C - rats administered with a dose of $60 \mathrm{mg} / \mathrm{kg}$ of pirimiphos-methyl; Group D - rats administered with a dose of $120 \mathrm{mg} / \mathrm{kg}$ of pirimiphos-methyl. ${ }^{*} \mathrm{p}<0.05$ vs. control (Group A).

Table 5

Progesterone levels (ng/ml) at different days of pregnancy in rats administered with pirimiphos-methyl during pregnancy.

\begin{tabular}{lcccc}
\hline & Group A & Group B & Group C & Group D \\
\hline Day 6 & $22.00 \pm 0.56$ & $17.70 \pm 1.19^{*}$ & $17.10 \pm 1.44^{*}$ & $11.60 \pm 0.77^{*}$ \\
Day 8 & $11.80 \pm 0.60$ & $13.00 \pm 1.69$ & $11.90 \pm 2.03$ & $13.00 \pm 2.38$ \\
Day 19 & $20.40 \pm 0.47$ & $16.60 \pm 0.74^{*}$ & $16.70 \pm 0.97^{*}$ & $2.10 \pm 0.35^{*}$ \\
\hline
\end{tabular}

Group A - rats in the control group administered with distilled water only; Group B - rats administered with a dose of $10 \mathrm{mg} / \mathrm{kg}$ of pirimiphos-methyl; Group C - rats administered with a dose of $60 \mathrm{mg} / \mathrm{kg}$ of pirimiphos-methyl; Group D - rats administered with administered with a dose of $120 \mathrm{mg} / \mathrm{kg}$ of pirimiphos-methyl. ${ }^{*} \mathrm{p}<0.05$ vs. control (Group A).

born $(\mathrm{p}<0.05)$ when compared with control. There was a significant $(\mathrm{p}<0.05)$ decrease in average litter size and birth index in group $C$ when compared with the control. There was no significant difference in gestation length when compared with control. The pups born to dams in group $\mathrm{C}$ were born weak and died before day 4 post-delivery, hence no result for viability and weaning indices. Maternal exposure to $120 \mathrm{mg} / \mathrm{kg}$ body weight (group D) showed an abortifacient activity as no dam had any litter when opened up on GD30.

Effect of PM on estradiol levels in pregnant rats. There was no significant difference in estradiol level in groups $\mathrm{B}, \mathrm{C}$ and $\mathrm{D}$ when compared with control on day 6 of pregnancy. However, on day 8, there was a significant $(\mathrm{p}<0.05)$ decrease in estradiol level in groups $\mathrm{B}, \mathrm{C}$ and $\mathrm{D}$ when compared with control. On day 19 , there was a significant $(p<0.05)$ decrease in estradiol level in groups B, C and D when compared with control as shown in Table 4.

Effect of PM on progesterone levels in pregnant rats. There was a significant $(p=0.0005)$ decrease in progesterone level in groups $\mathrm{B}, \mathrm{C}$ and $\mathrm{D}$ when compared with control on day 6 of pregnancy. However, on day 8 , there was no significant difference $(\mathrm{p}=0.9651)$ in progesterone level in groups $\mathrm{B}, \mathrm{C}$ and $\mathrm{D}$ when compared with control. On day 19 , there was a significant $(\mathrm{p}=0.0001)$ decrease in progesterone level in groups $\mathrm{B}, \mathrm{C}$ and $\mathrm{D}$ when compared with control as shown in Table 5.

Progesterone/estradiol ratio during pregnancy in rats exposed to PM. There was no significant decrease $(\mathrm{p}=0.0884)$ in progesterone/estradiol ratio in groups $\mathrm{B}, \mathrm{C}$ and $\mathrm{D}$ when compared with control on day 6 of pregnancy. However, on day 8 , there was a significant ( $\mathrm{p}=0.0001)$ increase in progesterone/estradiol ratio in groups $\mathrm{B}, \mathrm{C}$ and $\mathrm{D}$ when compared with control. On day 19 , there was a significant $(\mathrm{p}=0.0001)$ increase in progesterone/estradiol ratio in groups $\mathrm{B}$ 
and C when compared with control; however, group $\mathrm{D}$ was significantly decreased when compared with the control as shown in Table 6.

\section{Discussion}

The developmental process is particularly vulnerable to adverse environmental conditions including exposure to pesticides. Results from this study showed that administration of PM caused a decrease in the number of implantation sites on days 6 and 8 of pregnancy. There was also a decerase in fetal weight, crown-to-rump lenght, umbilical cord lenght and placenta weight on day 19 of pregnancy. At term, PM reduced offspring birth weight, decreased litter size and total number of pups born.

The reduction in the number of implantation sites seen can be attributed to the alteration in the endometrial environment, which is greatly contributed to, by the significant change in hormone milieu as seen in this study. It could also be due to the effect of the organophosphate on the blastocyst or the final stage of implantation (Paria et al. 1993; Carson et al. 2000). Decrease in progesterone/estradiol ratio affected the uterine receptivity thus leading to a decrease in the number of implantation sites. (Carson et al. 2000; Wang and Dey 2006). The roles of ovarian hormones cannot be overemphasized for uterine receptivity and implantation (Zhao et al. 2013). Progesterone is essential for the induction of uterine decidualization, which occurs during the peri-implantation period. The results of this study show that administration of PM during pregnancy caused a significant reduction in both estradiol and progesterone level at certain periods during gestation. Progesterone/estradiol ratio can be used as a good predictor for implantation success or failure. Low progesterone/estradiol ratio affects the number of implanting embryos in rats (Hamid et al. 2012). Although the reduction in progesterone/estradiol ratio on day 6 was not significant, it could be one of the factors that contributed to the reduced number of implants in the treated groups.
The reduction in the number of implants could also be attributed to decrease in glandular and luminal epithelial proliferation, which occurs as result of significant drop in progesterone level (MendozaRodriguez et al. 2003).

Significant reduction in fetal and birth weight is an indication of intra-uterine growth restriction (IUGR) in organophosphates-exposed rats (Lesage et al. 2004), which corroborates the results from this study. The IUGR in this study was not due to reduction of gestational length or preterm delivery since there was no significant difference in gestational length between the control and the treated groups (10 and $60 \mathrm{mg} / \mathrm{kg}$ body weight). Anticholinesterase agents such as organophosphates may also have a nonspecific regulatory effect on the growth, possibly by an influence on placental transport of nutrients. Pesticides have been shown to pass through the blood-brain barrier and placenta and have also been found in amniotic fluid (Bradman et al. 2003) indicating direct contact with the fetus. In groups administered after implantation, there was no significant difference in the number of fetuses in the treated groups when compared with control but growth was hampered as seen in the significant difference in fetal weight. Fetuses and neonates are more vulnerable to damaging effects of organophosphates because they have lower levels of detoxifying enzymes that deactivate organophosphates (Furlong et al. 2006; Holland et al. 2006). The placenta is responsible for the transfer of materials between fetal and maternal circulation. Therefore, the fetal growth is closely linked to the exchange roles of the placenta. The size of a fetus at birth directly reflects the net transfer of water and solutes across the placenta during the period of gestation (Desforges and Sibley 2010). This could also be attributed to influence of PM on placenta transport of nutrients as seen in the significant decrease in placenta weight in the treated groups when compared with control.

According to Chahoud and Paumgartten (2005), lower body weight on day 19 of pregnancy accompa-

Table 6

Progesterone/estradiol ratio at different days of pregnancy in rats administered with pirimiphos-methyl.

\begin{tabular}{lcccc}
\hline & Group A & Group B & Group C & Group D \\
\hline Day 6 & $3431.70 \pm 379.35$ & $2463.60 \pm 281.28$ & $2329.76 \pm 216.96$ & $2745.60 \pm 338.78$ \\
Day 8 & $594.50 \pm 46.90$ & $1914.50 \pm 166.93^{\star}$ & $1634.10 \pm 212.96^{\star}$ & $2334.80 \pm 338.78^{\star}$ \\
Day 19 & $748.80 \pm 48.71$ & $918.80 \pm 122.44^{\star}$ & $1110.70 \pm 190.53^{\star}$ & $354.30 \pm 41.77^{\star}$ \\
\hline
\end{tabular}

Group A - rats in the control group administered with distilled water only; Group B - rats administered with a dose of $10 \mathrm{mg} / \mathrm{kg}$ of pirimiphos-methyl; Group C - rats administered with a dose of $60 \mathrm{mg} / \mathrm{kg}$ of pirimiphos-methyl; Group D - rats administered with a dose of $120 \mathrm{mg} / \mathrm{kg}$ of pirimiphos-methyl. ${ }^{\star} \mathrm{p}<0.05$ vs. control (Group A). 
nied by a reduced crown-to-rump length indicate that the fetal development is retarded for gestational age, which is in line with the result from this study showing a significant reduction in fetal weight and crown-torump length (CRL) in all doses compared with the control. The umbilical cord is of importance for a normal fetal development. It has also been reported to be good indicator of fetal movement (Barron et al. 1991). A short cord has been associated with increased risk of fetal malformation, fetal distress and possibly placental abruption (Krakowiak et al. 2004; Olaya and Bernal 2015). The significant decrease in the length of umbilical cord in group $\mathrm{D}$, in addition to the decrease in placenta weight, could be another factor responsible for the decrease in fetal weight on GD19.

Prenatal exposure to organophosphate pesticides affects in utero and postpartum growth in many animals, e.g. reduced birth weight and reduced postpartum weight gain (Guney et al. 2007). The developmental process is particularly vulnerable to adverse environmental conditions including exposure to pesticides.

The results from this study showed that administration of PM to pregnant rats did not increase the gestation period. This is in agreement with some studies who found no association between gestational exposure to pesticides and duration of pregnancy (Grether et al. 1987; Fenster and Coye 1990; Thomas et al. 1992). However, some studies have shown that there was reduction in gestation length leading to preterm delivery after gestational exposure to pesticides (Eskenazi et al. 1999; Xiang et al. 2000; Dabrowski et al. 2003).

\section{Conclusion}

This study showed that administration of PM impaired pregnancy outcome such as fetal weight, birth weight, crown-to-rump length, umbilical cord length, litter size, and implantation in rats. The hormonal imbalance influences the process of implantation during the pregnancy as well as the pregnancy outcome in rats. This study therefore suggests that exposure to PM might impair the process of reproduction during pregnancy with probable long term effect on the offspring health. This study is of importance to public health since this chemical is widely used as pesticide.

\section{References}

Baldi I, Mohammed-Brahim B, Brochard P, Dartigues JF, Salamon R. Delayed health effects of pesticides: review of current epidemiological knowledge [in French]. Rev Epidemiol Sante Publique 46, 134-142, 1998.

Berkowitz GS, Obel J, Deych E, Lapinski R, Godbold J, Liu Z, Landrigan PJ, Wolff MS. Exposure to indoor pesticides during pregnancy in a multiethnic, urban cohort. Environ Health Perspect 111, 79-84, 2003.

Barron S, Foss J, Riley E. The Effect of prenatal cocaine exposure on umbilical cord length in fetal rats. Neurotoxicol Teratol 13, 503-506, 1991.

Bradman A, Barr DB, Claus Henn BG, Drumheller T, Curry C, Eskenazi B. Measurement of pesticides and other toxicants in amniotic fluid as a potential biomarker of prenatal exposure. Environ Health Perspect 111, 1779-1782, 2003

Cabello G, Valenzuela M, Vilaxa A, Duran V, Rudolph I, Hrepic N, Calaf G. A rat mammary tumor model induced by the organophosphorous pesticides parathion and malathion, possibly through acetylcholinesterase inhibition. Environ Health Perspect 109, 471-479, 2001.

Carson DD, Bagchi I, Dey SK, Enders AC, Fazleabas AT, Lessey BA, Koshinaga K. Embryo implantation. Dev Biol 223, 217-237, 2000.

Chahoud I, Paumgartten FJR. Relationships between fetal body weight of Wistar rats at term and the extent of skeletal ossification. Braz J Med Biol Res 38, 565-575, 2005.

Dabrowski S, Hanke W, Polanska K, Makowiec-Dabrowska T, Sobala W. Pesticide exposure and birthweight: an epidemiological study in Central Poland. Int J Occup Med Environ Health 16, 31-39, 2003.

Deb K, Reese J, Paria BC. Methodologies to study implantation in mice. Methods Mol Med 121, 9-34, 2006.

Desforges M, Sibley C. Placental nutrient supply and fetal development. Int J Dev Biol 54, 377-390, 2010.

Dey SK, Lim H, Das SK, Reese J, Paria BC, Daikoku T. Wang H. Molecular cues to implantation. Endocr Rev 25, 341-373, 2004.

Eskenazi B, Bradman A, Castorina R. Exposure of children to organophosphate pesticides and their potential adverse health effects. Environ Health Perspect 107, 409-419, 1999.

Fenster L, Coye MJ. Birthweight of infants born to Hispanic women employed in agriculture. Arch Environ Health $45,46-52,1990$. 
Furlong CE, Holland N, Richter RJ, Bradman A, Ho A, Eskenazi B. PON1 status of farmworker mothers and children as a predictor of organophosphate sensitivity. Pharmacogenet Genomics 16, 183-190, 2006.

Gallo MA, Lawryk NJ. Organic phosphorus pesticides. In Handbook of Pesticide Toxicology. Hayes WJJr. and Laws ER (Eds.), Academic Press, New York. 1991.

Grether JK, Harris JA, Neutra R, Kizer KW. Exposure to aerial malathion application and the occurrence of congenital anomalies and low birthweight. Am J Public Health 77, 1009-1010, 1987.

Guney M, Oral B, Demirin H, Take G, Giray SG, Altuntas I Mungan T. Fallopian damage induced by organophosphate insecticide methyl parathion, and protective effect of vitamins $\mathrm{E}$ and $\mathrm{C}$ on ultrastructural changes in rats. Toxicol Ind Health 23, 428-439, 2007.

Hamid HY, Zakaria MA, Yimer N, Meng GY, Haron AW, Mustapha NM. Effects of elevated ambient temperature on embryo implantation in rats. Afri J Biotechnol 11, 6624-6632, 2012.

Hayes J, Laws E. Handbook of Pesticide Toxicology. Academic Press, San Diego. 1991.

Holland N, Furlong C, Bastaki M, Richter R, Bradman A, Huen K. Paraoxonase polymorphisms, haplotypes, and enzyme activity in Latino mothers and newborns. Environ Health Perspect 114, 985-999, 2006.

Iranloye B, Oyeusi K. Alada A. Effect of aqueous extract of Phyllanthus amarus leaf on implantation and pregnancy in rats. Niger J Physiol Sci 25, 63-66, 2010.

Iranloye BO, Oyesola TO. The organophosphate - pirimiphos-methyl alters estrous cycle and hormone concentrations in female Sprague-Dawley rats. World Journal of Pharmaceutical and Life Sciences 4, 207-211, 2018.

Koch D, Lu C, Fisker-Andersen J, Jolley L, Fenske R. Temporal association of children's pesticide exposure and agricultural spraying: report of a longitudinal biological monitoring study. Environ Health Perspect 110, 829-833, 2002.

Krakowiak P, Smith EN, de BG, Lydon-Rochelle MT. Risk factors and outcomes associated with a short umbilical cord. Obstet Gynecol 103, 119-27, 2004.

Lesage J, Del-Favero F, Leonhardt M, Louvart H, Maccari S, Vieau D, Darnaudery M. Prenatal stress induces intrauterine growth restriction and programmes glucose intolerance and feeding behaviour disturbances in the aged rat. J Endocrinol 181, 291-296, 2004.

Mendoza-Rodriguez CA, Merchant-Larios H, Segura-Valdez ML, Moreno-Mendoza N, Cruz ME, Arteaga-Lopez P, Camacho-Arroyo I, Dominguez R, Cerbon M. c-fos and estrogen receptor gene expression pattern in the rat uterine epithelium during the estrous cycle. Mol Reprod Dev 64, 379-388, 2003.

Ngoula F, Watcho P, Dongmo MC, Kenfack A, Kamtchouing P, Tchoumboue J. Effects of pirimiphos-methyl (an organophosphate insecticide) on the fertility of adult male rats. Afr Health Sci 7, 3-9, 2007.

Olaya C, Bernal JE. Clinical associations to abnormal umbilical cord length in Latin American newborns. J Neonatal Perinatal Med 8, 251-256, 2015.

Paria BC, Huet H, Dey SK. Blastocyst's state of activity determines the "window" of implantation in the receptive mouse uterus. Proc Natl Acad Sci U S A 90, 10159-10162, 1993.

Pope CN. Organophosphorous pesticides: do they all have the same mechanism of toxicity? J Toxicol Environ Health B Crit Rev 2, 161-181, 1999.

Recio R, Ocampo-Gomez G, Moran-Martinez J, Borja-Aburto V, Lopez-Cervantes M, Uribe M, Torres-Sanchez L, Cebrian ME. Pesticide exposure alters follicle-stimulating hormone levels in Mexican agricultural workers. Environ Health Perspect 113, 1160-1163, 2005.

Sanborn MD, Cole D, Abelsohn A, Weir E. Identifying and managing adverse environmental health effects: 4 . Pesticides Can Med Assoc J 166, 1431-1436, 2002.

Tamura H, Maness SC, Reishman K, Dorman DC, Gray LE, Gaido KW. Androgen receptor antagonism by the organophosphate insecticide fenilrothion. Toxicol Sci 60, 56-62, 2001.

Thomas D, Petitti D, Goldhaber M, Swan S, Rappaport E, Hertz-Picciotto I. Reproductive outcomes in relation to malathion spraying in the San Francisco Bay area, 1981-1982. Epidemiology 3, 32-39, 1992.

Wang H, Dey SK. Roadmap to embryo implantation: clues from mouse models. Nat Rev Genet 7, 185-199, 2006.

Xiang H, Nuckols JR, Stallones LA. Geographic information assessment of birth weight and crop production patterns around mother's residence. Environ Res 82, 160-167, 2000.

Zhao LH, Cui XZ, Yuan HJ, Liang B, Zheng LL, Liu YX, Luo MJ. Tan JH. Restraint stress inhibits mouse implantation: temporal window and the involvement of HB-EGF, estrogen and progesterone. PLoS One 8, e80472, 2013. 